\title{
Antimicrobial susceptibility testing of Haemophilus influenzae: trial organised as part of United Kingdom national external quality assessment scheme for microbiology
}

\author{
J J S SNELL, D F J BROWN,* T J PHUA
}

From the Division of Microbiological Reagents and Quality Control, Central Public Health Laboratory, Colindale, and the *Clinical Microbiology and Public Health Laboratory, Addenbrooke's Hospital, Cambridge

SUMMARY Six strains of Haemophilus influenzae were distributed to 417 United Kingdom laboratories who were asked to test susceptibility of the strains to ampicillin, augmentin, tetracycline, chloramphenicol, and trimethoprim and to test for $\beta$ lactamase production. Laboratories were also asked to provide details of their methods by completing a questionnaire. The incidence of reports recording sensitive strains as resistant was $8 \%$ (ampicillin), 7\% (augmentin), 3\% (tetracycline), $1 \%$ (chloramphenicol), and $12 \%$ (trimethoprim). The incidence of reports recording resistant strains as sensitive was $9 \%$ (ampicillin), (2\% with $\beta$ lactamase producing strains, $24 \%$ with non- $\beta$ lactamase producing strains), $51 \%$ (augmentin), 10\% (tetracycline), 20\% (chloramphenicol), and 3\% (trimethoprim). High error rates were associated with several methods or practices. These included use of general purpose growth media rather than susceptibility testing media and failure to add lysed blood to the media when testing trimethoprim susceptibility; standardise the inoculum; use suitable control strains; and the use of high content discs for testing chloramphenicol, tetracycline, and ampicillin.

The United Kingdom national external quality assessment scheme for microbiology (UKNEQAS) has been described previously. ${ }^{12}$ As part of the general bacteriology section of the scheme participants were asked to perform antimicrobial susceptibility tests on strains of established susceptibility. Results of tests on strains of Staphylococcus aureus, Pseudomonas aeruginosa, and Enterobacteriaceae showed high error rates with some strain and antimicrobial agent combinations, differences in interlaboratory error rates, and association between certain methods or practices and error rates. ${ }^{34}$ The species of bacteria distributed were robust and easy to cultivate. Results were not necessarily representative of those obtained with more fastidious organisms such as Haemophilus influenzae. A study by Philpott-Howard et al ${ }^{5}$ entailing 25 selected laboratories had found higher error rates in the detection of resistance to tetracycline,

Accepted for publication 27 March 1986 ampicillin, and chloramphenicol in $H$ influenzae than had been generally found with less fastidious organisms distributed in the UKNEQAS. ${ }^{34} \mathrm{~A}$ trial was organised in September 1985 to investigate the standard of performance of susceptibility testing of $H$ influenzae and factors affecting the results in a large number of laboratories in the United Kingdom.

\section{Material and methods}

LABORATORIES PARTICIPATING

All laboratories enrolled in the UKNEQAS participated in the trial but only the results of United Kingdom laboratories $(n=417)$ were included in this analysis. The type and geographical distribution of the laboratories have been described previously. ${ }^{1}$

ORGANISMS

Six strains of $H$ influenzae were distributed as freeze dried cultures. Before despatch the susceptibility of the strains to antimicrobial agents was determined in 
Table 1 Results of susceptibility tests, as determined by the reference laboratories and reported by the participating laboratories

\begin{tabular}{|c|c|c|c|c|c|c|c|c|c|}
\hline & \multicolumn{2}{|c|}{ Reference laboratory results } & \multirow{3}{*}{$\begin{array}{l}\text { Designated } \\
\text { correct } \\
\text { result }\end{array}$} & \multirow{2}{*}{\multicolumn{5}{|c|}{ No of laboratories reporting strains as }} & \multirow{3}{*}{$\begin{array}{l}\text { Percentage } \\
\text { correct }\end{array}$} \\
\hline & \multirow{2}{*}{$\begin{array}{l}\text { Minimum } \\
\text { inhibitory } \\
\text { concentration } \\
(\mathrm{mg} / \mathrm{l})\end{array}$} & \multirow[t]{2}{*}{$\begin{array}{l}\beta \text { lactamase } \\
\text { production }\end{array}$} & & & & & & & \\
\hline & & & & Sensitive & Intermediate & Resistant & Positive & Negative & \\
\hline $\begin{array}{l}M Q C L 1136 \\
\text { Ampicillin } \\
\text { Augmentin } \\
\text { Tetracycline } \\
\text { Chloramphenicol } \\
\text { Trimethoprim } \\
\beta \text { lactamase }\end{array}$ & $\begin{array}{l}0.25 \\
0.5 \\
16 \\
8 \\
0.06\end{array}$ & Negative & $\begin{array}{l}\text { S } \\
\mathbf{S} \\
\mathbf{R} \\
\mathbf{R} \\
\mathbf{S} \\
\text { Negative }\end{array}$ & $\begin{array}{r}347 \\
255 \\
29 \\
69 \\
280\end{array}$ & $\begin{array}{l}4 \\
0 \\
2 \\
7 \\
0\end{array}$ & $\begin{array}{r}28 \\
16 \\
313 \\
282 \\
69\end{array}$ & 2 & 318 & $\begin{array}{l}92 \\
94 \\
91 \\
79 \\
80 \\
99\end{array}$ \\
\hline $\begin{array}{l}M Q C L 1137 \\
\text { Ampicillin } \\
\text { Augmentin } \\
\text { Tetracycline } \\
\text { Chloramphenicol } \\
\text { Trimethoprim } \\
\beta \text { lactamase }\end{array}$ & $\begin{array}{l}8 \\
1 \\
1 \\
0.5 \\
0.03\end{array}$ & Positive & $\begin{array}{l}\mathbf{R} \\
\mathbf{S} \\
\mathbf{S} \\
\mathbf{S} \\
\mathbf{S} \\
\text { Positive }\end{array}$ & $\begin{array}{r}6 \\
245 \\
335 \\
354 \\
333\end{array}$ & $\begin{array}{l}0 \\
2 \\
0 \\
0 \\
0\end{array}$ & $\begin{array}{r}374 \\
30 \\
9 \\
5 \\
17\end{array}$ & 332 & 12 & $\begin{array}{l}98 \\
88 \\
97 \\
99 \\
95 \\
97\end{array}$ \\
\hline $\begin{array}{l}M Q C L 1138 \\
\text { Ampicillin } \\
\text { Augmentin } \\
\text { Tetracycline } \\
\text { Chloramphenicol } \\
\text { Trimethoprim } \\
\beta \text { lactamase }\end{array}$ & $\begin{array}{l}2 \\
1 \\
2 \\
0.5 \\
0.06\end{array}$ & Positive & $\begin{array}{l}\mathbf{R} \\
\mathbf{S} \\
\mathbf{S} \\
\mathbf{S} \\
\mathbf{S} \\
\text { Positive }\end{array}$ & $\begin{array}{r}12 \\
243 \\
336 \\
354 \\
322\end{array}$ & $\begin{array}{l}2 \\
2 \\
0 \\
0 \\
1\end{array}$ & $\begin{array}{r}361 \\
28 \\
5 \\
2 \\
24\end{array}$ & 329 & 13 & $\begin{array}{l}97 \\
89 \\
99 \\
99 \\
93 \\
96\end{array}$ \\
\hline $\begin{array}{l}\text { MQCL } 1139 \\
\text { Ampicillin } \\
\text { Augmentin } \\
\text { Tetracycline } \\
\text { Chloramphenicol } \\
\text { Trimethoprim } \\
\beta \text { lactamase }\end{array}$ & $\begin{array}{l}8 \\
32 \\
2 \\
0 \cdot 25 \\
0 \cdot 1\end{array}$ & Negative & $\begin{array}{l}\mathbf{R} \\
\mathbf{R} \\
\mathbf{S} \\
\mathbf{S} \\
\mathbf{S} \\
\text { Negative }\end{array}$ & $\begin{array}{r}85 \\
133 \\
321 \\
350 \\
265\end{array}$ & $\begin{array}{l}5 \\
5 \\
0 \\
0 \\
0\end{array}$ & $\begin{array}{r}282 \\
132 \\
19 \\
5 \\
80\end{array}$ & 6 & 330 & $\begin{array}{l}76 \\
49 \\
94 \\
99 \\
77 \\
98\end{array}$ \\
\hline $\begin{array}{l}M Q C L 1140 \\
\text { Ampicillin } \\
\text { Augmentin } \\
\text { Tetracycline } \\
\text { Chloramphenicol } \\
\text { Trimethoprim } \\
\beta \text { lactamase }\end{array}$ & $\begin{array}{l}0.25 \\
0.25 \\
1 \\
0.25 \\
0.03\end{array}$ & Negative & $\begin{array}{l}\text { S } \\
\text { S } \\
\text { S } \\
\text { S } \\
\text { Negative }\end{array}$ & $\begin{array}{l}342 \\
261 \\
334 \\
354 \\
327\end{array}$ & $\begin{array}{l}5 \\
1 \\
0 \\
0 \\
0\end{array}$ & $\begin{array}{r}28 \\
8 \\
7 \\
2 \\
20\end{array}$ & 1 & 322 & $\begin{array}{l}91 \\
97 \\
98 \\
99 \\
94 \\
99\end{array}$ \\
\hline $\begin{array}{l}\text { MQCL 1141 } \\
\text { Ampicillin } \\
\text { Augmentin } \\
\text { Tetracycline } \\
\text { Chloramphenicol } \\
\text { Trimethoprim } \\
\beta \text { lactamase }\end{array}$ & $\begin{array}{l}0 \cdot 25 \\
1 \\
8 \\
8 \\
32\end{array}$ & Negative & $\begin{array}{l}\mathbf{S} \\
\mathbf{S} \\
\mathbf{R} \\
\mathbf{R} \\
\mathbf{R} \\
\text { Negative }\end{array}$ & $\begin{array}{r}334 \\
253 \\
37 \\
69 \\
9\end{array}$ & $\begin{array}{l}6 \\
1 \\
4 \\
9 \\
0\end{array}$ & $\begin{array}{r}38 \\
19 \\
303 \\
281 \\
341\end{array}$ & 3 & 320 & $\begin{array}{l}88 \\
93 \\
88 \\
78 \\
97 \\
99\end{array}$ \\
\hline
\end{tabular}

$\mathrm{S}=$ sensitive; $\mathbf{R}=$ resistant.

the Division of Microbiological Reagents and Quality Control (DMRQC) and the Clinical Microbiology and Public Health Laboratory, Cambridge. Minimum inhibitory concentrations were determined by serial dilution of the antimicrobial agents in solid medium by a method based on that of Ericsson and Sherris, ${ }^{6}$ but the medium used was Oxoid Isosensitest agar supplemented with $5 \%$ chocolated horse blood. Production of $\beta$ lactamase was examined by both an acidimetric paper strip method (Mast Laboratories) and a chromogenic cephalosporin paper "stick" method (Oxoid). Table 1 shows reference laboratory results.

REPORT FORMS AND QUESTIONNAIRE

A report form was provided for each strain. Five antimicrobial agents were listed, and participants were requested to test any that they would normally 
Table 2 No and percentage of laboratories achieving various percentages of their total possible scores

\begin{tabular}{lc}
\hline $\begin{array}{l}\text { Percentage of total possible } \\
\text { score achieved }\end{array}$ & $\begin{array}{l}\text { No (and \%) of laboratories } \\
\text { achieving: }\end{array}$ \\
\hline $51-55$ & $1(0 \cdot 3)$ \\
$56-60$ & $2(0 \cdot 5)$ \\
$61-65$ & $4(1 \cdot 0)$ \\
$66-70$ & $10(2 \cdot 6)$ \\
$71-75$ & $11(2 \cdot 9)$ \\
$76-80$ & $10(2 \cdot 6)$ \\
$81-85$ & $21(5 \cdot 5)$ \\
$86-90$ & $54(14 \cdot 0)$ \\
$91-95$ & $112(29 \cdot 1)$ \\
$96-100$ & $160(41 \cdot 5)$ \\
\hline
\end{tabular}

test and to report their results as sensitive or resistant. Results for $\beta$ lactamase production were also requested, if normally tested. A questionnaire covering details of antimicrobial susceptibility testing methods was sent with the cultures to all participants.

\section{SCORING SCHEME}

Antimicrobial agents

For each strain and antimicrobial agent combination a correct result of sensitive or resistant was designated on the basis of minimum inhibitory concentration and $\beta$ lactamase determinations by the reference laboratories (table 1). $\beta$ lactamase producing strains were regarded as resistant to ampicillin regardless of the minimum inhibitory concentration. The results from each laboratory were assessed at DMRQC, and each result recorded as sensitive or resistant was marked as correct if it was the same as the designated correct result, and as incorrect if different. Results recorded as "intermediate" were not marked.

\section{Blactamase production}

Participants' results recorded as positive or negative were marked as correct if they were the same as those of the reference laboratory, and as incorrect if different.

\section{MEASUREMENT OF ASSOCIATION BETWEEN METHODS AND RESULTS}

The association between methods and results was tested by the $\chi^{2}$ test to compare the ratios of correct: incorrect results achieved by laboratories using different methods. Unless otherwise stated, the numbers of correct and incorrect results were the combined totals from all strains with all antimicrobial agents. To avoid distortions due to small numbers of laboratories using a particular method association between methods and error rates were tested only when methods were used by a minimum of 20 laboratories. Results achieved with methods used by less than 20 laboratories, or when methods used were not unequivocally stated, have generally not been included in text or tables. The exclusion of these results causes some apparent inconsistency where the sum of laboratories using specific techniques is less than the total using the general method. Thus-for example, although 283 laboratories stated that the used control organisms, only two species were used by more than 20 laboratories, the Oxford strain of staphylococcus by 173 , and $H$ influenzae by $74 ;$ the apparent shortfall of 36 laboratories comprising those using other species, more than one species, or not supplying the required information.

Table 3 Distribution of incorrect results with trimethoprim and tetracycline according to media used

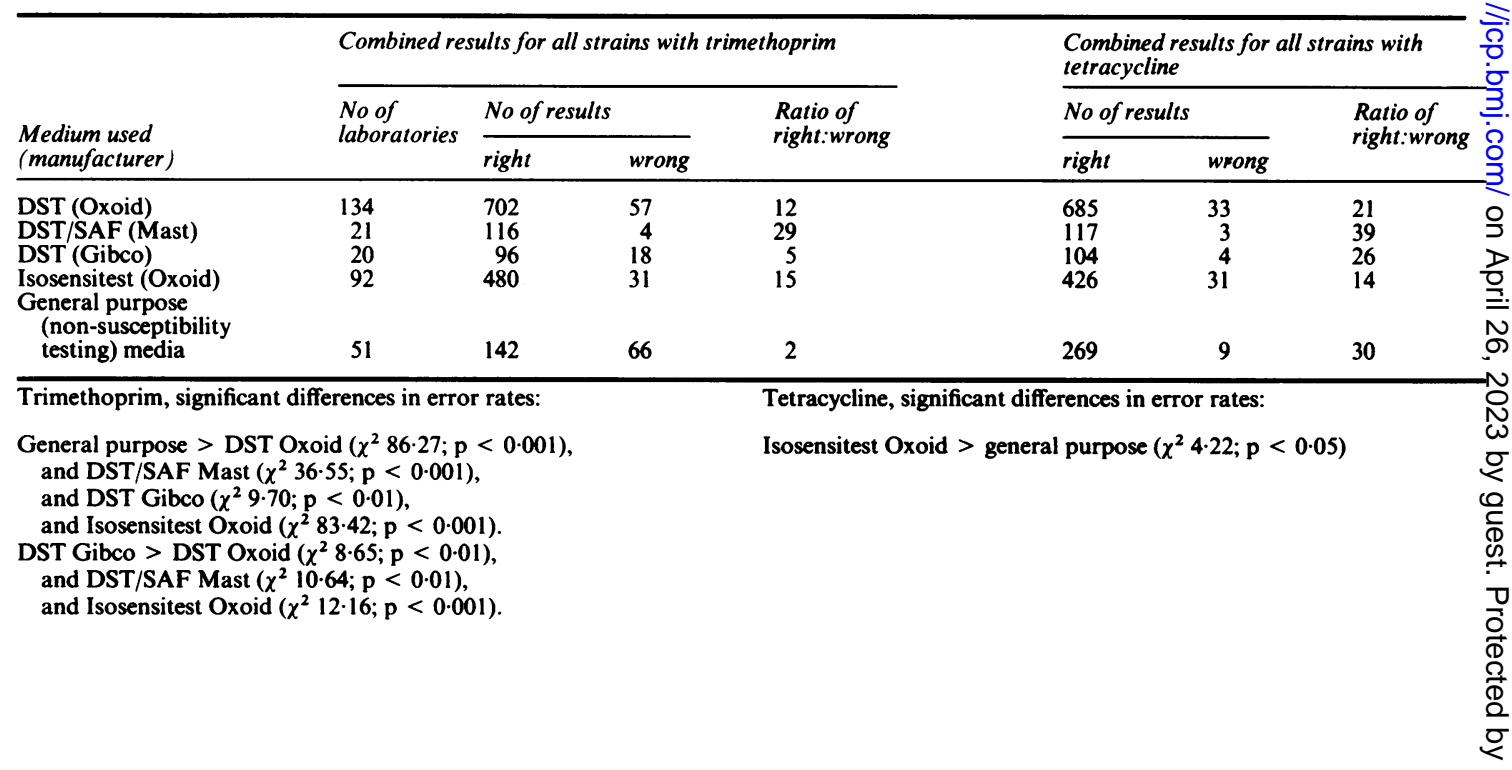


Table 4 Distribution of incorrect results according to use of lysed blood

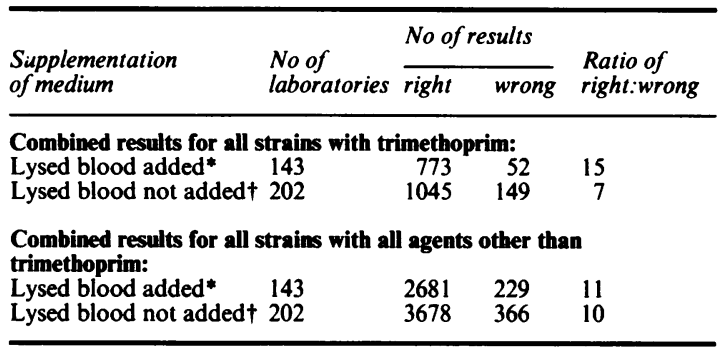

*Lysed blood alone, 67 laboratories; lysed blood + nicotinamide adenosine, 56; lysed blood + "chocolated" blood, 15; lysed blood + whole blood, 5 .

+Whole blood, 10 laboratories; "chocolated" blood, 190; Fildes extract, 1 ; nicotinamide adenosine, 1 .

\section{Results}

\section{DISCREPANCY RATES}

Table 1 shows the results and error rates of participants for the six strains distributed. The overall error rate for all strain and antimicrobial agent combinations was $8 \%$. Table 2 shows the numbers of laboratories achieving various percentages of the possible number of correct results. Standards of performance in testing these strains varied considerably, with $26 \%$ of laboratories achieving $90 \%$ or less of results that were correct.

\section{METHOD OF TESTING}

A disc method was used by 361 laboratories, a breakpoint method by seven, and a combination of these methods by four.

\section{MEDIA}

Association between medium used and error rates was found only with trimethoprim and tetracycline (table 3). Media specifically designated for susceptibility testing performed better than general purpose media in trimethoprim testing. A larger proportion of incorrect results were also associated with trimethoprim, using Diagnostic Sensitivity Test Agar (DST) (Gibco) than with other susceptibility testing media. Tetracycline susceptibility tests on Isosensitest agar were associated with incorrect results slightly more often than with tests on general purpose media $\left(\chi^{2} 4 \cdot 22 ; p<0.05\right)$.

\section{LYSED BLOOD}

Table 4 shows the distribution of correct and incorrect results according to the addition of lysed blood to the medium. Laboratories adding lysed blood to medium made proportionally fewer errors than those not adding lysed blood when testing trimethoprim $\left(\chi^{2} 20.75 ; \mathrm{p}<0.001\right)$. There was no significant difference in error rates between those adding lysed blood and those not adding lysed blood for the combined results with antimicrobial agents other than trimethoprim.

\section{INCUBATION ATMOSPHERE}

Table 5 shows the atmospheres used for incubation, together with the distribution of correct and incorrect results for each of them. Laboratories using carbon dioxide sachets made proportionally more errors than those incubating in air $\left(\chi^{2} 72.29 ; p<0.001\right)$, in candle jars $\left(\chi^{2} 38.69 ; \mathrm{p}<0.001\right)$, or in carbon dioxide incubators $\left(\chi^{2} 91.80 ; \mathrm{p}<0.001\right)$.

\section{INOCULUM}

The 245 laboratories that prepared inocula by emulsifying growth in fluid made proportionally fewer errors (5923 correct, 502 incorrect results, ratio of corrent:incorrect 12) than the 109 laboratories that used growth direct from the colony as an inoculum (2495 correct, 327 incorrect results, ratio of correct: incorrect 8) $\left(\chi^{2} 34 \cdot 22, \mathrm{p}<0.001\right)$.

\section{STANDARDISATION OF THE INOCULUM}

The 289 laboratories stating that they made some attempt at standardising the inoculum ( 232 by eye, four with opacity tubes, 12 by measured dilution, six by incubation for a fixed period, 13 by touching a fixed number of colonies, and 22 by other or unspecified methods) made proportionally fewer errors (6874 correct, 612 incorrect results, ratio of correct:incorrect 11) than the 80 laboratories not attempting standardisation (1890 correct, 261 incorrect results, ratio of correct:incorrect 7$)\left(\chi^{2} 31 \cdot 78\right.$; $\mathrm{p}<0.001)$.

\section{APPLICATION OF INOCULUM}

Table 6 shows the distribution of correct and incorrect results according to the method of application of the inoculum. Those applying the inoculum by swab made proportionally fewer errors than those using a loop $\left(\chi^{2} 13.54 ; p<0.001\right)$.

Table 5 Distribution of incorrect results according to atmosphere of incubation

\begin{tabular}{|c|c|c|c|c|}
\hline \multirow{2}{*}{$\begin{array}{l}\text { Incubation } \\
\text { atmosphere }\end{array}$} & \multirow{2}{*}{$\begin{array}{l}\text { No of } \\
\text { laboratories }\end{array}$} & \multicolumn{2}{|c|}{ No of results } & \multirow{2}{*}{$\begin{array}{l}\text { Ratio of } \\
\text { right:wrong }\end{array}$} \\
\hline & & right & wrong & \\
\hline \multirow{3}{*}{$\begin{array}{l}\text { Air } \\
\text { Candle jar } \\
\text { Carbon dioxide } \\
\text { incubator } \\
\text { Carbon dioxide- } \\
\text { producing sachet }\end{array}$} & $\begin{array}{l}74 \\
46\end{array}$ & $\begin{array}{l}1824 \\
1016\end{array}$ & $\begin{array}{l}157 \\
108\end{array}$ & $\begin{array}{r}12 \\
9\end{array}$ \\
\hline & 223 & 5384 & 481 & 11 \\
\hline & 21 & 441 & 114 & 4 \\
\hline
\end{tabular}


Table 6 Distribution of incorrect results according to method of application of inoculum

\begin{tabular}{lrlll}
\hline & No of & \multicolumn{2}{l}{ No of results } & \\
\cline { 3 - 5 } $\begin{array}{l}\text { Inoculum } \\
\text { applied by }\end{array}$ & laboratories & right & wrong & $\begin{array}{l}\text { Ratio of } \\
\text { right:wrong }\end{array}$ \\
\hline Loop & 51 & 1212 & 148 & 8 \\
Swab & 201 & 4829 & 407 & 12 \\
Loop (spread by swab) & 88 & 2054 & 203 & 10 \\
\hline
\end{tabular}

USE OF CONTROLS

Table 7 shows the distribution of correct and incorrect results, according to the use of control organisms. Those using a strain of $H$ influenzae as a control organism made proportionally fewer errors than those using the Oxford strain of $S$ aureus $\left(\chi^{2} 31.94\right.$; $\mathrm{p}<0.001)$ and those using no controls at all $\left(\chi^{2} 21.77 ; \mathrm{p}<0.001\right)$. There was no significant difference between the error rates of 176 laboratories that used a control strain on the same plate as the test strains (4165 correct, 385 incorrect results, ratio of correct:incorrect 11) and the 99 laboratories that used control strains on a separate plate from the test strains (2427 correct, 250 incorrect results, ratio of correct:incorrect 10 ). The 220 laboratories using controls on each occasion of testing made proportionally fewer errors (5239 correct, 489 incorrect results, ratio of correct:incorrect 11) than the 53 laboratories using controls less often (1278 correct, 145 incorrect, ratio of correct:incorrect 9$)\left(\chi^{2} 3.85 ; \mathrm{p}<0.05\right)$.

MEASUREMENT OF ZONE SIZES

The 170 laboratories who measured zone sizes - that is, those who always measured zones and those who measured zones of inhibition only if the zone of the test strain was obviously smaller than that of the control-made proportionally fewer errors (4191 correct, 340 incorrect, ratio of correct:incorrect 12) than the 141 laboratories that did not measure zones (3269 correct, 377 incorrect results, ratio of correct: incorrect 9) $\left(\chi^{2} 20 \cdot 31 ; p<0.001\right)$.

TESTS FOR $\beta$ LACTAMASE PRODUCTION

The 326 laboratories using a separate test for $\beta$ lactamase production made proportionally fewer
Table 7 Distribution of correct results according to use of controls

\begin{tabular}{|c|c|c|c|c|}
\hline \multirow[b]{2}{*}{ Control } & \multirow{2}{*}{$\begin{array}{l}\text { No of } \\
\text { laboratories }\end{array}$} & \multicolumn{2}{|c|}{ No of results } & \multirow{2}{*}{$\begin{array}{l}\text { Ratio of } \\
\text { right:wrong }\end{array}$} \\
\hline & & right & wrong & \\
\hline $\begin{array}{l}\text { Oxford strain of } \\
\text { Staphylococcus } \\
\text { aureus } \\
\text { Haemophilus }\end{array}$ & 173 & 4045 & 447 & 9 \\
\hline $\begin{array}{l}\text { influenzae } \\
\text { Controls not used }\end{array}$ & $\begin{array}{l}74 \\
88\end{array}$ & $\begin{array}{r}1865 \\
235\end{array}$ & $\begin{array}{r}112 \\
21\end{array}$ & $\begin{array}{l}17 \\
11\end{array}$ \\
\hline
\end{tabular}

errors in testing susceptibility to ampicillin (1743 correct, 152 incorrect results, ratio of correct:incorrect 11) than the 42 laboratories not using a separate test (193 correct, 34 incorrect, ratio of correct:incorrect 6) $\left(\chi^{2} 12.26 ; \mathrm{p}<0.001\right)$. There was no significant difference in error rates between the 139 laboratories using a chromogenic cephalosporin disc or stick (793 correct, 10 incorrect results, ratio of correct:incorrect 79 ) and the 149 laboratories using acidimetric strips or discs (825 correct, 15 incorrect, ratio of correct:incorrect 55) for the detection of $\beta$ lactamase production.

\section{DISCS}

The 289 laboratories using single discs made proportionally fewer errors (6918 correct, 646 incorrecto ratio of correct:incorrect 11 ) than the 49 laboratorie using multiple discs (1113 correct, 155 incorrect, rati⿳亠 of correct:incorrect 7$)\left(\chi^{2} 17.87 ; p<0.001\right)$. There was no significant difference in error rates between the 185 laboratories using discs manufactured by Oxoid (4291 correct, 414 incorrect, ratio of correct:incorrect $10)$ and the 127 laboratories using discs manufactured by Mast (3077 correct, 338 incorrect, ratio of correct:incorrect nine). Table 8 shows the amounts of antimicrobial agent in the discs used and the associated error rates. Those using low content $(2 \mu \mathrm{g})$ ampicillin discs made proportionally fewer errors in testing ampicillin susceptibility than those using discs of higher content $(5,10,25 \mu \mathrm{g})\left(\chi^{2} 18.94 ; \mathrm{p}<0.001\right)$. Those using low content $(2 \cdot 5,5,10 \mu \mathrm{g})$ chloramphenicol discs made proportionally fewer errors in testing chloramphenicol susceptibility than those

Table 8 Distribution of incorrect results according to disc content

\begin{tabular}{|c|c|c|c|c|c|}
\hline \multirow[b]{2}{*}{ Antimicrobial agent } & \multirow[b]{2}{*}{ Disc content $(\mu g)$} & \multirow{2}{*}{$\begin{array}{l}\text { No of } \\
\text { laboratories }\end{array}$} & \multicolumn{2}{|c|}{ No of results } & \multirow{2}{*}{$\begin{array}{l}\text { Ratio of } \\
\text { right:wrong }\end{array}$} \\
\hline & & & right & wrong & \\
\hline $\begin{array}{l}\text { Ampicillin } \\
\text { Chloramphenicol } \\
\text { Tetracycline }\end{array}$ & $\begin{array}{l}2 \\
5,10,25 \\
2 \cdot 5,5,10 \\
25,30,50 \\
5,10 \\
25,30,50\end{array}$ & $\begin{array}{r}145 \\
188 \\
212 \\
131 \\
258 \\
64\end{array}$ & $\begin{array}{r}805 \\
948 \\
1181 \\
661 \\
1446 \\
328\end{array}$ & $\begin{array}{r}50 \\
124 \\
48 \\
93 \\
68 \\
32\end{array}$ & $\begin{array}{r}16 \\
8 \\
25 \\
7 \\
21 \\
10\end{array}$ \\
\hline
\end{tabular}


using discs of higher content $(25,30,50 \mu \mathrm{g})\left(\chi^{2} 50 \cdot 26\right.$; $\mathrm{p}<0.001)$. Those using low content $(5,10 \mu \mathrm{g})$ tetracycline discs made proportionally fewer errors in testing tetracycline susceptibility than those using discs of higher content $(25,30,50 \mu \mathrm{g})\left(\chi^{2} 11 \cdot 13 ; \mathrm{p}<\right.$ $0.001)$. There were insufficient laboratories using disc contents other than $30 \mu \mathrm{g}$ for augmentin, or higher than $5 \mu \mathrm{g}$ for trimethoprim, to permit comparison between results of tests with low and high content discs.

\section{Discussion}

The results indicate serious problems in the testing of susceptibility of $H$ influenzae. The incidence of reports recording sensitive strains as resistant was $8 \%$ (ampicillin), 7\% (augmentin), 3\% (tetracycline), 1\% (chloramphenicol), and $12 \%$ (trimethoprim). The incidence of reports recording resistant strains as sensitive was $9 \%$ (ampicillin) (2\% with $\beta$ lactamase producing strains, $24 \%$ with the non- $\beta$ lactamase producing strain), $51 \%$ (augmentin), 10\% (tetracycline), $20 \%$ (chloramphenicol), and 3\% (trimethoprim). These figures contrast with those obtained in a previous study ${ }^{5}$ when the incidence of reports recording sensitive strains as resistant was $0.5 \%$ (tetracycline), $1.6 \%$ (ampicillin), and 6.2\% (trimethoprim); the incidence of reports recording resistant strains as sensitive was $37 \%$ (tetracycline), $27 \%$ (ampicillin), and $67 \%$ (trimethoprim). The error rates obtained in the two studies are not strictly comparable, however, as in the earlier study ${ }^{5}$ results were obtained from strains referred to a reference laboratory after routine testing by a selected group of 25 laboratories. The current study entailed a small number of selected strains tested by a large number of laboratories. Whatever the exact discrepancy rate, spurious reports of sensitivity for the strains resistant to chloramphenicol, tetracycline, ampicillin, and augmentin are disturbing as such errors could have a profound effect on the outcome of treatment. Resistance to ampicillin mediated by $\beta$ lactamase production was recognised by an average of $98 \%$ laboratories compared with only $76 \%$ recognising intrinsic resistance in a $\beta$ lactamase negative strain. Reporting of the $\beta$ lactamase negative strain as sensitive to augmentin by $51 \%$ of laboratories is inconsistent, as augmentin is likely to be more effective than ampicillin against $H$ influenzae only when the strain produces $\beta$ lactamase. These errors are probably explained by the common use of higher content discs $(30 \mu \mathrm{g}$, of which $20 \mu \mathrm{g}$ is amoxycillin) for augmentin than for ampicillin $(2 \mu \mathrm{g}$ and $10 \mu \mathrm{g}$ most commonly used).

Only 11 laboratories used a breakpoint method alone or in combination with a disc method, thus precluding a comparison of results obtained by those using breakpoint methods with those using disc methods. Such a comparison would have been useful in assessing whether the claimed advantages of the breakpoint methods over disc diffusion methods would give more reliable results with this group of fastidious organisms.

Association between the use of various media and results was largely confined to trimethoprim testing in that laboratories using media specially designed for susceptibility testing made fewer errors than those using general purpose growth media. We were unable to confirm a previous report ${ }^{5}$ that tetracycline resistance in $H$ influenzae could be more reliably detected by the use of Oxoid Isosensitest agar than with Oxoid DST agar. Reduction in error rates in testing trimethoprim susceptibility, resulting from the addition of lysed horse blood to the medium, was not unexpected. This effect is well known and has been shown in previous trials with Enterobacteriacea $e^{34}$ and $H$ influenzae. ${ }^{5}$

The high error rate associated with the use of carbon dioxide producing sachets is unexplained. Incubation of tests in an atmosphere containing carbon dioxide produced by other methods gave results no worse than when tests were incubated in air. The results with the carbon dioxide producing sachets clearly warrant further investigation.

As in previous trials ${ }^{34}$ methods of preparation, standardisation, and application of the inoculum all influenced the error rate. These factors are likely to influence the density of growth, which is critical in disc susceptibility testing. ${ }^{8}$ The use of a strain of $H$ influenzae as a control organism on each occasion of testing was important in reducing the error rate. Those using the Oxford strain of $S$ aureus did not make proportionally fewer errors than those not using a control. There is no generally recognised control strain of $H$ influenzae available; so we have deposited the sensitive strain (MQCL 1140) in the National Collection of Type Cultures (NCTC strain No 11931) for this purpose.

The influence of the amount of antimicrobial agent in the disc on error rates was evident. The use of high content discs was associated with high error rates with chloramphenicol, tetracycline, and ampicillin. Problems associated with the use of high content discs are well known. ${ }^{89}$ Augmentin discs with high content only $(30 \mu \mathrm{g})$ are currently commercially available from stock (other contents might be made to order). This seems excessively high compared with the recommended ${ }^{10} 2 \mu \mathrm{g}$ content for ampicillin discs. We understand from the manufacturers that $3 \mu \mathrm{g}$ augmentin discs will soon be commercially available.

The high error rates found in this and a previous trial $^{5}$ suggest that reproducible results might be difficult to achieve by the use of the disc method with 
$H$ influenzae. In the present trial, however, $41 \%$ of laboratories achieved error rates of less than $5 \%$, and $25 \%$ made no errors. Thus reliable results can be obtained with the disc method provided that certain aspects of technique are followed. Care must be exercised in the interpretation of results from surveys such as this since only a few strains were examined, and apparent differences in the efficacy of particular aspects of technique may reflect interactions of technical factors rather than a single factor. The following recommendations, however, are supported by the results of this survey and that of previous work. ${ }^{5}$ They are in line with recommendations based on previous surveys. ${ }^{34}$

1 Media specially designed for susceptibility testing should be used rather than general purpose growth media.

2 Lysed blood should be added to the media when testing for susceptibility to trimethoprim.

3 The density of the inoculum should be standardised.

4 A control strain of $H$ influenzae should be used on each occasion of testing.

5 Low content discs should be used for testing chloramphenicol $(2 \cdot 5,5$, or $10 \mu \mathrm{g})$, tetracycline (5 or $10 \mu \mathrm{g})$ ampicillin $(2 \mu \mathrm{g})$ and augmentin $(2 \mu \mathrm{g}$ ampicillin $+1 \mu \mathrm{g}$ clavulonic acid when these become commercially available).

We thank other members of the antibiotic susceptibility testing subcommittee of the steering committee for National External Quality Assessment in Microbiology for advice.

Members of the subcommittee are: Dr ID Farrell (chairman), Mr JJS Snell (secretary), Dr DFJ Brown,
Mr P Donnelly, Dr R George, and Dr AC Scott.

\section{References}

1 Snell JJS, de Mello JV, Gardner PS. The United Kingdom national microbiological quality assessment scheme. $J$ Clin 0 Pathol 1982;35:82-93.

2 Snell JJS. United Kingdom National External Quality Assess- $\frac{\overline{\bar{N}}}{\overline{0}}$ ment Scheme for Microbiology. Eur J Clin Microbiol $\frac{\sigma}{\supset}$ 1985;4:464-7.

3 Snell JJS, Brown DFJ, Gardner PS. An antibiotic susceptibility testing trial organized as part of the United Kingdom national $\omega$ external microbiological quality assessment scheme. J Clin $\overrightarrow{0}$ Pathol 1982;35:1169-76.

4 Snell JJS, Brown DFJ, Gardner PS. Comparison of results from $\overrightarrow{\vec{\omega}}$ two antibiotic susceptibility testing trials that formed part of $\sigma$ the United Kingdom national external quality assessment $\frac{0}{0}$
scheme. J Clin Pathol 1984;37:321-8.

5 Philpott-Howard J, Seymour A, Williams JD. Accuracy of methods used for susceptibility testing of Haemophilus influenzae in United Kingdom laboratories. J Clin Pathol 1983;36:1105-10.

6 Ericsson HM, Sherris JC. Antibiotic sensitivity testing. Report of an International Collaborative Study. Acta Pathol Microbiol 응 Scand [B] 1971;217 (suppl):1-90.

7 Waterworth PM. Changes in sensitivity testing. $J$ Antimicrob $\overrightarrow{-}$ Chemother 1983;11:1-3.

8 Brown DFJ, Blowers R. Disc methods of sensitivity testing and other semiquantitative methods. In: Reeves DS, Phillips I, $\mathbb{D}$ Williams JD, Wise R, eds. Laboratory methods in antimicrobial chemotherapy. Edinburgh: Churchill Livingstone, 1978:8-30.

9 Waterworth PM. Laboratory control. In: Garrod LP, Lambert HP, O'Grady F, eds. Antibiotics and chemotherapy. Edinburght Churchill Livingstone, 1981:464-504.

10 Williams JD, Kattan S. Haemophilus species. In: Reeves DS Phillips I, Williams JD, Wise R, eds. Laboratory methods $\dot{\mathbf{m}}$ antimicrobial chemotherapy. Edinburgh: Churchill Living stone, 1978:106-11.

Requests for reprints to: Mr JJS Snell, Division of

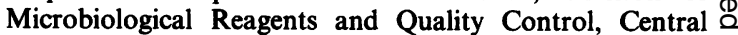
Public Health Laboratory, 61 Colindale Avenue, London $\overrightarrow{\vec{O}}$ NW9 5HT, England. 